\title{
POSTURES OF UPPER EXTREMITY CORRELATED WITH CARPAL TUNNEL SYNDROME (CTS)
}

\section{CHIA-LIANG CHIANG ${ }^{1}$, CHU-YUNG LIAO ${ }^{2}$, and HSIEN-WEN KUO ${ }^{3,4}$}

${ }^{1}$ China Medical University, Taichung, Taiwan

College of Public Health, Institute of Environmental Health

${ }^{2}$ Chung Chou University of Science and Technology, Yuanlin, Taiwan

College of Health, Department of Early Childhood Educare

${ }^{3}$ National Yang-Ming University, Taipei, Taiwan

School of Medicine, Institute of Environmental and Occupational Health Sciences

${ }^{4}$ National Defense Medical Center, Taipei, Taiwan

School of Public Health

\begin{abstract}
Objectives: Non-medical hospital staff members are in frequent contact with patients and therefore are required to perform a wide variety of repetitive and high-frequency activities. The objective of this study was to assess the relationships between upper extremity activity and carpal tunnel syndrome (CTS) among non-medical hospital staff members. Material and Methods: Carpal tunnel syndrome in 144 non-medical hospital staff members was diagnosed using the Nordic Musculoskeletal Questionnaire (NMQ), a physician's diagnosis, physical examination (Tinel's signs and Phalen test) and a nerve conduction velocity (NCV) test. In addition, an ergonomic assessment was performed and a video camera was used to record the physical activities at work. Results: The prevalence rate of CTS was highest for the NMQ (51.9\%), followed by physician's diagnosis (49.5\% for the right hand, $29.9 \%$ for the left hand), physical examination $(54.7 \%)$, and nerve conduction test (motor nerve $27.5 \%$ and $25 \%$, sensory nerve $21.7 \%$ and $15 \%$, for right and left hands, respectively). Based on logistic regression models for the NMQ and physician's diagnoses, there was a dose-dependently higher risk of CTS with the upper extremity index among participants, but this was non-significant based on the physical examination and nerve conduction tests. Conclusions: Nerve conduction velocity is the gold standard in diagnosis of CTS, but use of NMQ and physician's diagnosis may overestimate the incidence of CTS in workers who have been engaging in repetitive stress activities for a relatively short time. Int J Occup Med Environ Health 2017;30(2):281-290
\end{abstract}

Key words:

Carpal tunnel syndrome, Musculoskeletal disorders, Nerve conduction velocity, Ergonomic stress, Tinel's signs, Phalen test

\section{INTRODUCTION}

Carpal tunnel syndrome (CTS) is a common entrapment neuropathy resulting from compression of the median nerve in the wrist. The causes of CTS are not fully understood but a number of the ailments that affect the local architecture of the wrist are associated with it, including rheumatoid arthritis and Colles fractures. It is also common among workers whose jobs involve repetitive and forceful hand movements. Office and business machinery were the leading sources of work-related CTS (42\% of

Received: January 12, 2015. Accepted: April 26, 2016.

Corresponding author: H.-W. Kuo, National Yang-Ming University, School of Medicine, Institute of Environment and Occupational Health Sciences, No. 155, Sec. 2, Linong Street, Taipei, 112 Taiwan (e-mail: hwkuo@ym.edu.tw). 
classifiable sources) in every economic sector except construction, followed by hand tools (20\%) [1].

There have been numerous previous studies which examined the possible implications of typing-related postures and activities on CTS incidence [2]. Fourteen percent of Americans have experienced dull pain, sharp pain or numbness in both or one of the hands. However, based on nerve conduction studies and electromyography, CTS prevalence was as low as $2.7 \%$ [3].

A work operation can be defined as highly repetitive if the cycle time to complete 1 unit is $\leq 30 \mathrm{~s}$, or if $>50 \%$ of the cycle time is spent performing the same repetitive motion [4]. Therefore, people whose jobs involve this sort of highly repetitive activity are more susceptible to CTS. Even those who do not engage in highly repetitive motion activities suffer from CTS if they are involved in different kinds of motions that are bad for the wrist. Velocities during typing in flexion/extension plane, when the nerve is compressed by thickening of the flexor tendon sheaths, are similar to velocities in workers involved in industrial activities who are at risk of suffering CTS [5,6].

Although the nature of the work in hospital administrative offices is varied and may not meet the definition of repetitive work, there may still be damage to tendons in the hands and wrist through repeated stretching and elongation. In addition, administration workers in Taiwanese hospitals are often required to wear office uniforms and shoes, such as tight skirts and high-heels, which do not always allow for unrestricted movement. Office staff may also be required to frequently fetch and replace files from large filing cabinets which may require a large range of movement from crouching to standing on tip-toe. This has led to widespread complaints of musculoskeletal discomfort or pain among non-medical hospital staff [7].

As such, hospital managers need to address the needs of their staff in terms of their occupational injuries or symptoms, evaluate the scale of the problem and determine the risk factors. Nerve conduction studies are frequently used to confirm the clinical diagnosis of CTS, and as a measure of patient progress in clinical trials [8]. However, the correlations between nerve conduction study (NCS) and both the questionnaire and physical examination are weak to moderate. The objective of this study was to assess the relationship between upper extremity motion in nonmedical hospital staff members and the risk of developing CTS using the 4 diagnostic methods.

\section{MATERIAL AND METHODS}

\section{Subjects}

One hundred twenty-nine of the 144 non-medical hospital staff members at a teaching hospital participated in this study. The participation rate was approximately $90 \%$. From the initial walkthrough, jobs were classified into 3 groups based on working characteristics:

- administrative unit (including finance and repair services personnel),

- medical unit (including reception and medical records), - service unit (including consulting and transferals).

Exclusion criteria included an underlying disease such as rheumatoid arthritis, diabetes, gout or hypothyroidism, renal dialysis, pregnancy, space-occupying lesions such as a ganglion, and previous fracture of the distal radius.

\section{Measurements}

A signed informed consent was obtained from each subject. Nordic Musculoskeletal Questionnaire (NMQ) [9], modified to include other risk factors, such as demographic data, use of oral contraception, regularity of menstruation, method of child delivery, domestic chores, and frequency of exercise. All of the participants were evaluated for CTS using the 3 diagnostic methods:

- occupational therapist conducted differential diagnosis of pain symptoms by soft-touch palpation of the pain spot in the wrist or upper extremity and collecting further information on pain symptoms, pain severity, pain duration, normal activity affected (yes/no), and 
undergoing treatment (yes/no). To maintain objectivity, the physician was unaware of the job description of each of the examinees;

- the physical examination included Tinel's signs and the Phalen test;

- motor and sensory nerve conduction tests were performed based on the procedures previously described.

Nerve conduction velocity (NCV) was assessed using a Medelec MS 60 machine (Vickers Medical Ltd., London, UK) at a room temperature of $25^{\circ} \mathrm{C}$. Nerve conduction velocity consisted of palmar sensory and routine motor NCVs for both the median and ulnar nerve. All median nerve NCV abnormalities were based on absolute and relative latency findings (>0.4 ms) [10]. The participants underwent a standardized electrophysiological examination and physical assessments that were performed blind by a board-certified technician to ensure consistency of results. All NCV procedures were conducted in accordance with American Association of Electrodiagnostic Medicine (AAEM) guidelines for measurement, temperature, safety precautions, and electrode placement [11,12].

An ergonomic assessment on wrist or hand was performed for all non-medical staff members at the hospital. Each participant was clearly asked for the frequency (times/ $\min$ ) and duration (min/day) of workers' physical movements for various motions (check operation, overhead grasping motion, fixing operation, adjusting files, sorting operation and arm lifting). These data were confirmed using a video camera.

Observations were also conducted to monitor and record the frequency and duration of motions. The following 12 upper extremity postures and motions were evaluated: neck fixed point, eyes fixed on a computer monitor, shoulder fixed point, keying, using photocopier, using ink chop, arm extension, checking paper work, handling documents, filing, taking medical charts, sorting charts or documents. The upper extremity index (UEI) was calculated by multiplying the frequency (times/min) and duration (min/day) of the postures/ motions per day. There were 3 main groups based on UEI: low exposure ( $\leq 100$ times/day), moderate exposure (101240 times/day) and high exposure ( $\geq 241$ times/day).

\section{Statistical analyses}

All data were recorded using Excel software and analyzed by SPSS 12. A Chi ${ }^{2}$ test was used to compare the demographics of the 3 groups. The prevalence rates of CTS were calculated based on the 4 criteria. Univariate and multiple logistic regression models were used to determine which factors affected CTS.

\section{RESULTS}

Table 1 compares the demographic data of the 3 groups. Work duration was significantly associated with the 3 groups but all the other factors were not significant. Most of the non-medical hospital staff members in the service unit were under 30 years of age (71.4\%), while the majority of the other participants were aged 30-40 years. The lowest percentage of participants with a body mass index $(\mathrm{BMI}) \geq 25$ was in the service unit $(5.7 \%)$. The highest percentage of married participants was in the administration unit. Work duration was longest in the administration unit, followed by the medical and service units.

Table 2 compares the CTS prevalence rates among non-medical hospital staff members using the 4 diagnostic methods. The prevalence rates of CTS were highest for NMQ questionnaire method (51.9\%), followed by the physician's diagnosis $(49.5 \%$ and $29.9 \%$, for right and left hands, respectively), physical examination $(54.7 \%$ ) and NCV (motor nerve: $27.5 \%$ and $25 \%$, sensory nerve: $21.7 \%$ and $15 \%$, for right and left hands, respectively).

Table 3 shows upper body postures and motions in nonmedical staff associated with pain symptoms in CTS diagnosis using NMQ questionnaire. Risk of CTS symptoms was most significantly associated with overhead grasping motions (odds ratio $(\mathrm{OR})=2.64$ ), adjusting 
Table 1. Characteristics of respondents taking part in the study of the relationships between upper extremity activity and carpal tunnel syndrome (CTS) among non-medical hospital staff members

\begin{tabular}{|c|c|c|c|c|}
\hline \multirow[t]{2}{*}{ Variable } & \multicolumn{3}{|c|}{$\begin{array}{l}\text { Respondents in work group } \\
\qquad(\mathrm{N}=129) \\
{[\mathrm{n}(\%)]}\end{array}$} & \multirow[t]{2}{*}{$\mathrm{p}$} \\
\hline & $\begin{array}{c}\text { administrative } \\
(\mathrm{N}=29)\end{array}$ & $\begin{array}{c}\text { medical } \\
(\mathrm{N}=65)\end{array}$ & $\begin{array}{c}\text { service } \\
(\mathrm{N}=35)\end{array}$ & \\
\hline Age [years] & & & & n.s. \\
\hline$<30$ & $9(31.0)$ & $14(21.5)$ & $25(71.4)$ & \\
\hline $30-40$ & $14(48.3)$ & $34(52.3)$ & $10(28.6)$ & \\
\hline$\geq 40$ & $6(20.7)$ & $7(12.2)$ & $0(0.0)$ & \\
\hline \multicolumn{5}{|l|}{ Body mass index $\left[\mathrm{kg} / \mathrm{m}^{2}\right]$} \\
\hline$<25$ & $24(82.7)$ & $56(86.2)$ & $33(94.3)$ & \\
\hline$\geq 25$ & $5(17.3)$ & $9(13.8)$ & $2(5.7)$ & \\
\hline Education time [years] & & & & n.s. \\
\hline$\leq 12$ & $10(34.5)$ & $17(26.2)$ & $9(25.7)$ & \\
\hline$\geq 13$ & $19(65.5)$ & $48(73.8)$ & $26(74.3)$ & \\
\hline Marital status & & & & n.s. \\
\hline unmarried & $9(31.0)$ & $37(57.0)$ & $18(51.4)$ & \\
\hline married & $20(69.0)$ & $28(43.0)$ & $17(48.6)$ & \\
\hline Activity frequency [days/week] & & & & n.s. \\
\hline$<3$ & $19(65.5)$ & $49(75.4)$ & $29(82.9)$ & \\
\hline $3-7$ & $7(24.2)$ & $13(20.0)$ & $6(17.1)$ & \\
\hline$\geq 7$ & $3(10.3)$ & $3(4.6)$ & $0(0.0)$ & \\
\hline Work duration [years] & & & & $<0.05$ \\
\hline$<1$ & $3(10.3)$ & $8(12.3)$ & $10(28.6)$ & \\
\hline $1-4$ & $8(27.7)$ & $26(40.0)$ & $14(40.0)$ & \\
\hline $5-8$ & $15(51.7)$ & $24(36.9)$ & $10(28.6)$ & \\
\hline$\geq 9$ & $3(10.3)$ & $7(10.8)$ & $1(2.8)$ & \\
\hline Work time $[\mathrm{h} /$ week] & & & & n.s. \\
\hline$<40$ & $4(13.8)$ & $8(12.3)$ & $1(2.9)$ & \\
\hline $40-44$ & $23(79.3)$ & 49 (75.4) & $31(88.6)$ & \\
\hline$\geq 44$ & $2(6.9)$ & 8 (12.3) & $3(8.5)$ & \\
\hline
\end{tabular}

n.s. - not statistically significant.

files $(\mathrm{OR}=2.17)$, and arm lifting $(\mathrm{OR}=2.75)$. Overall, the ORs and confidence intervals (CIs) were $>1$. Slight associations with risk of CTS were found for checking, organizing, and sorting documents or medical charts. The ORs were $>1$, but the CIs were in the borderline range. The postures of standing, sitting and kneeling did not significantly correlate with any risk of CTS.
Table 4 shows the factors affecting the risk of CTS based on multiple logistic regression models for each of the 4 diagnostic criteria. The factors included into the models were: work unit, age, education level, work duration, marital status, BMI and UEI. Based on the questionnaire and the physician's diagnosis, UEI correlated significantly with the risk of CTS in a dose-dependent manner. However, 
Table 2. Prevalence rates of carpal tunnel syndrome determined using the four diagnostic methods among non-medical hospital staff members

\begin{tabular}{|c|c|c|}
\hline \multirow{2}{*}{ Diagnostic method } & \multicolumn{2}{|c|}{ Respondents } \\
\hline & $\mathrm{n}$ & $\%$ \\
\hline Questionnaire $(\mathrm{N}=129)$ & 67 & 51.9 \\
\hline Physician's diagnosis $(\mathrm{N}=97)$ & 77 & 79.4 \\
\hline right hand & 48 & 49.5 \\
\hline left hand & 29 & 29.9 \\
\hline Physical examinations $(\mathrm{N}=117$ ) & 64 & 54.7 \\
\hline positive/positive & 38 & 32.5 \\
\hline positive/negative & 26 & 22.2 \\
\hline Motor nerve conduction velocity $(\mathrm{N}=120)$ & 63 & 52.5 \\
\hline right hand & 33 & 27.5 \\
\hline left hand & 30 & 25.0 \\
\hline Sensory nerve conduction velocity $(\mathrm{N}=120)$ & 44 & 36.7 \\
\hline right hand & 26 & 21.7 \\
\hline left hand & 18 & 15.0 \\
\hline
\end{tabular}

$\mathrm{N}$ - number of study subjects.

Table 3. Carpal tunnel syndrome (CTS) diagnosed using self-reported questionnaire affected by various upper extremity postures among non-medical hospital staff

\begin{tabular}{|c|c|c|c|}
\hline \multirow[b]{2}{*}{ Posture of upper extremity } & \multicolumn{2}{|c|}{ Respondents } & \multirow[b]{2}{*}{ OR $(95 \% \mathrm{CI})$} \\
\hline & $\begin{array}{c}\text { total } \\
(\mathrm{N}=129) \\
{[\mathrm{n}]}\end{array}$ & $\begin{array}{c}\text { with CTS } \\
{[\mathrm{n}(\%)]}\end{array}$ & \\
\hline \multicolumn{4}{|l|}{ Check operation } \\
\hline yes & 49 & $26(53.1)$ & $1.08(0.53-2.18)$ \\
\hline no & 80 & $41(51.3)$ & 1 \\
\hline \multicolumn{4}{|l|}{ Overhead grasping motion } \\
\hline yes & 38 & $26(68.4)$ & $2.64 *(1.202-5.80)$ \\
\hline no & 91 & $41(45.1)$ & 1 \\
\hline \multicolumn{4}{|l|}{ Fixing operation } \\
\hline yes & 50 & $30(60.0)$ & $1.70(0.83-3.48)$ \\
\hline no & 79 & $37(46.8)$ & 1 \\
\hline \multicolumn{4}{|l|}{ Adjusting file } \\
\hline yes & 40 & $26(65.0)$ & $2.17^{* *}(1.01-4.67)$ \\
\hline no & 89 & $41(46.1)$ & 1 \\
\hline \multicolumn{4}{|l|}{ Sorting operation } \\
\hline yes & 46 & $28(60.9)$ & $1.76(0.85-3.64)$ \\
\hline no & 83 & $39(47.0)$ & 1 \\
\hline \multicolumn{4}{|l|}{ Arm lifting } \\
\hline yes & 58 & $38(65.5)$ & $2.75 *(1.35-5.60)$ \\
\hline no & 71 & $29(40.8)$ & 1 \\
\hline
\end{tabular}

OR - odds ratio; $\mathrm{CI}$ - confidence interval.

${ }^{*} \mathrm{p}<0.05 ; * \mathrm{p}<0.01$. 
Table 4. Risk factors correlated with carpal tunnel syndrome based on four diagnostic methods using multiple logistic regression adjusted by education level, age, marital status and body mass index

\begin{tabular}{lcccc}
\hline \multirow{2}{*}{ Variable } & \multicolumn{4}{c}{$\begin{array}{c}\text { Diagnostic method } \\
\text { OR }(95 \% \text { CI })\end{array}$} \\
\cline { 2 - 5 } & questionnaire & $\begin{array}{c}\text { physician's } \\
\text { diagnosis }\end{array}$ & $\begin{array}{c}\text { physical } \\
\text { examination }\end{array}$ & $\begin{array}{c}\text { nerve } \\
\text { conduction velocity }\end{array}$ \\
\cline { 2 - 5 } $\begin{array}{l}\text { Work group } \\
\text { administrative }\end{array}$ & 1 & & & 1 \\
$\quad$ medical & $4.30^{*}(1.29-14.32)$ & $1.10(0.33-3.62)$ & $0.86(0.25-2.94)$ & $1.05(0.23-4.68)$ \\
$\quad$ service & $4.62^{*}(1.23-17.45)$ & $1.59(0.44-5.71)$ & $1.13(0.30-4.33)$ & $5.05^{*}(1.05-24.28)$ \\
Work duration [years] & & & & 1 \\
$<1$ & 1 & 1 & 1 & 1 \\
$1-4$ & $3.29(0.89-12.14)$ & $0.82(0.21-3.18)$ & $1.38(0.36-5.38)$ & $2.62(0.37-18.39)$ \\
$5-8$ & $1.57(0.47-5.24)$ & $0.96(0.27-3.41)$ & $1.61(0.44-5.88)$ & $4.14(0.65-26.36)$ \\
$\geq 9$ & $1.42(0.16-12.46)$ & $0.89(0.77-10.40)$ & $3.23(0.19-54.11)$ & $10.73(0.62-185.85)$ \\
Upper extremity index (UEI) & & & & 1 \\
$\quad$ low & 1 & 1 & 1 & $1.82(0.38-8.63)$ \\
moderate & $4.14^{*}(1.11-15.43)$ & $2.52(0.68-9.31)$ & $0.80(0.21-3.11)$ & $1.56(0.23-10.68)$ \\
high & $12.93^{* *}(2.58-64.85)$ & $6.65^{*}(1.40-31.56)$ & $0.48(0.10-2.28)$ & \\
\hline
\end{tabular}

Low UEI: $\leq 100$ times/day; moderate UEI: 101-240 times/day; high UEI: $\geq 241$ times/day.

$\mathrm{OR}$ - odds ratio; $\mathrm{CI}$ - confidence interval.

${ }^{*} \mathrm{p}<0.05 ; * \mathrm{p}<0.01$.

the risk of CTS and UEI did not correlate significantly based on the CTS physical examination and NCV. Service unit and medical unit workers had significantly higher risks of CTS compared to workers in the administrative unit, based on NMQ questionnaire and NCV. However, no association was found for the physician's diagnosis and physical examination. Work duration was associated in a dose-dependent manner with the risk of CTS based on NCV and physical examinations, but this association was not statistically significant. Age, education level, marital status and BMI did not correlate with the risk of CTS.

\section{DISCUSSION}

There have been few studies on the prevalence of cumulative trauma disorders (CTDs) among non-medical hospital staff members. Due to recent changes in office technology, workplace and equipment design, office workers are required to do an increasing amount of work requiring varied physical movement, especially joint flexion/extension, abduction/adduction, and supination/pronation of the wrist with inadequate time to recover. Approximately 3000 patients visit this hospital every day, which places a high workload on non-medical staff.

In our study, non-medical staff members were divided into 3 groups based on workplace design. The medical unit is in frequent contact with visitors and therefore is required to perform a wide variety of tasks involving repetitive and high-frequency activities. These processes, which are often highly repetitive, cause adjacent tendons to slide against one another. The friction force is proportional to the tension in the tendon and inversely proportional to the curvature radius [13]. Thus, staff members frequently complained of symptoms related to CTDs, such as neck and shoulder stiffness, soreness of the hand or wrist, and low back pain. The diagnosis of CTS is clinical and based on the proper interpretation of symptoms and signs, with confirmation 
by electro-diagnostic testing [14]. The prevalence rates of CTS may vary according to the diagnostic tools used. Our data showed that the prevalence of CTS was highest using the NMQ questionnaire and lowest for NCV. The prevalence rate of CTS was also found to be higher in the right hand compared to the left hand using NCV. In the current study, motor or sensory NCV $>0.4 \mathrm{~ms}$ indicated that the individual had CTS.

Compared to the NMQ questionnaire, NCV has a higher fluctuation in sensitivity and specificity (49-84\% and 95\%, respectively). In the current study, NCV value acts as the gold standard for diagnosis of CTS, while sensitivity and specificity values of the physical examinations were higher than those of the NMQ questionnaire (data not shown). Based on multiple logistic regression models, the factor that affected CTS, according to the NMQ questionnaire, was dose-dependent with the UEI.

However, this factor did not correlate significantly with CTS diagnosis using physical examinations and NCV tests. Physical examinations and NCV tests showed that CTS correlated positively with work duration, but the correlation was not significant. Nerve conduction velocity tests were far more objective diagnostic tools for CTS than any of the other three, all of which involved some degree of subjectivity.

Previous studies $[15,16]$ showed subjects with CTS in different stages (even early - that depended on the applied technique) with damage to the median nerve detected using NCV test, whereas the NMQ questionnaire may only reveal suspected CTS. Although the reliability of the NMQ has been shown to be acceptable on specific characteristics of work strain, CTS is unsuitable to diagnose using standardized NMQ for the analysis of musculoskeletal symptoms. Because none of the subjects in this study suffered from peripheral or ulnar neuropathy, pronator syndrome, thoracic outlet syndrome, cervical radiculopathy, arthritis, or metabolic or endocrine disorders, we are confident that CTS was not associated with any of these conditions.
Only 2 subjects took oral contraception and therefore related hormonal factors can be ruled out as a cause of CTS. Carpal tunnel syndrome in non-medical hospital staff was shown to be associated only with ergonomic stress, even if the motions were not repetitive in nature but were varied in their activities, and/or inappropriate or poor postures. These may be harmful to the median nerve.

Ergonomic stress in the current study was evaluated using a questionnaire and field observation as well as video recordings. The questionnaires measured the frequency and duration of 12 postures and/or movements in which the workers engaged.

The workers in our study were not involved in repetitive stress activities and therefore the BRIEF (Baseline Risk Identification of Ergonomic Factors) tool could be not accurately used to assess ergonomic stress. As an alternative to measuring ergonomic stress, an exposure index (EI) was calculated by multiplying frequency and duration of motion. Field observation and video recordings were used to confirm the results.

Latko et al. (1999) [17] rated the ergonomic stress of 352 workers involved in repetitive activities in 3 manufacturing facilities on a 10-point visual analog scale $(0-10,10=$ most stressful $)$ and found that the odds ratio of high versus low repetition was 2.32 , and repetition was significantly associated with the prevalence of CTS. Our findings, using the NMQ questionnaire and physician's diagnosis, were consistent with Latko et al.'s results with regard to the dose-dependent effect of CTS and repetition. We found no significant associations of the upper extremity index (UEI) with CTS using physical examinations and NCV. This may be due to the clinical progression of CTS which involves 3 phases: the preclinical phase, phases of nerve compression, and the phase of irreversible damage. It is well-established that anthropometric data varies among different populations. The cutoff point in the current study was $0.4 \mathrm{~ms}$ (distal sensory latency of the median nerve minus the distal sensory latency of 
the ulnar nerve), whereas previous studies [18,19] used different cutoff points $(0.5 \mathrm{~ms}$ and $0.26 \mathrm{~ms}$, respectively). Girlanda et al. (1998) [20] reported a sensitivity of $92 \%$ for diagnosis of mild idiopathic CTS when the NCV and distalproximal ratio were combined. Resende et al. (2000) [19] used a new technique which compared the distal motor latency of the median nerve to the second lumbrical muscle (L2) with the distal motor latency of the ulnar nerve to the interossei muscle (INT).

Ultrasonographic examination of the median nerve seems to be a promising method in the diagnosis of CTS, assessing the morphologic changes of the median nerve in patients with clinical signs and symptoms. Quantitative ultrasonography assessment of CTS diagnosis was used in patients with negative electrodiagnostic test findings, especially in the early stage of CTS [21]. The alternative technique proposed is more sensitive and simpler than conventional techniques for detecting CTS, and should be incorporated into thermography [22] and computed tomography [23]. However, these methods are not very common and cannot be conclusively substantiated without further study.

Some limitations were found in this study. Firstly, ergonomic assessment among non-medical hospital staff may not accurately measure in each posture during all work duration, especially including intensity and posture of activities, workload and impact for musculoskeletal function. Future studies need to give consideration to the subjectivity of respondents' reported pain, which may confound results. Secondly, it was often difficult to determine whether a particular movement or posture was the cause of the pain, or whether the pain caused the subjects to adopt a more comfortable and/or incorrect posture or movement. Further research should be performed to provide a comprehensive understanding of what combinations of trigger factors should be modified and to evaluate the impact of workstation redesign using video recordings, as well as to reveal the interrelationships between different factors that contribute to the development of CTS.

\section{CONCLUSIONS}

The prevalence rates of CTS among hospital healthcare practitioners determined using the nerve conduction velocities tests were $27.5 \%, 25 \%$ (motor nerve) and $21.7 \%, 15 \%$ (sensory nerve), for right and left hands, respectively. There was a dose-response relationship between ergonomic stress (UEI) and CTS detected using the NMQ and physician's diagnoses, but there were no associations with physical examination and NCV. However, CTS diagnosis was confirmed by positive NCV results, while the questionnaire alone is able to indicate the cases of suspected CTS. It is necessary to periodically monitor ergonomic stress among healthcare practitioners with a view to decrease it and reduce the incidence of CTS.

\section{ACKNOWLEDGMENTS}

The authors are grateful for the assistance from the staffs and all participants in the hospital cooperating in this study.

\section{REFERENCES}

1. Wellman H, Davis L, Punnett L, Dewey R. Work-related carpal tunnel syndrome (WR-CTS) in Massachusetts, 19921997: Source of WR-CTS, outcomes, and employer intervention practices. Am J Ind Med. 2004;45(2):139-52, https://doi. org/10.1002/ajim.10326.

2. Fagarasanu M, Kumar S. Musculoskeletal symptoms in support staff in a large telecommunication company. Work. 2006;27(2):137-42.

3. Davis L, Wellman H, Punnett L. Surveillance of work-related carpal tunnel syndrome in Massachusetts, 1992-1997: A report from the Massachusetts Sentinel Event Notification System for occupational risks (SENSOR). Am J Ind Med. 2001;39(1):58-71, https://doi.org/10.1002/1097-0274(200101) 39:1<58::AID-AJIM6>3.0.CO;2-3. 
4. Silverstein BA, Fine LJ. Cumulative trauma disorders of the upper extremity. J Occup Med. 1991;33(5):642-4.

5. Serina E, Tal R, Rampel D. Wrist and forearm postures and motions during typing. Ergonomics. 1999;42(7):938-51, https://doi.org/10.1080/001401399185225.

6. Ugbolue UC, Nicol AC. A wrist tendon travel assessment of hand movements associated with industrial repetitive activities. Work. 2012;42(3):311-20, https://doi.org/10.3233/ WOR-2012-1429.

7. Chu PC, Fuh HR, Luo JC, Du CL, Chuang HY, Guo HR, et al. The impact of occupational health service network and reporting system in Taiwan. Int J Occup Environ Health. 2013;19(4): 352-62, https://doi.org/10.1179/2049396713Y.0000000043.

8. Eftekharsadat B, Ahadi T, Raissi GR, Shakoory SK, Fereshtehnejad SM. Validity of current electrodiagnostic techniques in the diagnosis of carpal tunnel syndrome. Med J Islam Repub Iran. 2014;28:45.

9. Kuorinka I, Jonsson B, Kilbom A, Vinterberg H, Biering-Sorensen F, Andersson G, et al. Standardized Nordic questionnaires for the analysis of musculoskeletal symptoms. Appl Ergon. 1987;18(3):233-7.

10. Di Benedetto M, Mitz M, Klingbeil G, Davidoff D. New criteria for sensory nerve conduction especially useful in diagnosing carpal tunnel syndrome. Arch Phys Med Rehabil. 1986;67(9):586-9.

11. Wainner RS, Fritz JM, Irrgang JJ, Delitto A, Allison S, Boninger ML. Development of a clinical prediction rule for the diagnosis of carpal tunnel syndrome. Arch Phys Med Rehabil. 2005;86(4):609-18, https://doi.org/10.1016/ j.apmr.2004.11.008.

12. Jablecki CK, Andary MT, So YT, Wilkins DE, Williams FH; AAEM Quality Assurance Committee. Literature review of the usefulness of nerve conduction studies and electromyography for the evaluation of patients with carpal tunnel syndrome. Muscle Nerve. 1993;16(12):1392-414, https://doi. org/10.1002/mus.880161220.

13. Hadler NM. Clinical concepts in regional musculoskeletal illness. Orlando: Grune \& Stratton; 1987.
14. Keleş I, Karagülle Kendi AT, Aydin G, Zöğ SG, Orkun S. Diagnostic prediction of ultrasonography in patients with carpal tunnel syndrome. Am J Phys Rehabil. 2005;84(6):443-50.

15. Gerawarapong C. Comparison of sensitivities between median-thumb sensory distal latency and conventional nerve conduction studies in electrodiagnosis of carpal tunnel syndrome. J Med Assoc Thai. 2014;97(9):969-76.

16. Atroshi I, Gummesson C, Johnsson R, McCabe SJ, Ornstein E. Severe carpal tunnel syndrome potentially needing surgical treatment in a general population. J Hand Surg. 2003;28(4):639-44, https://doi.org/10.1016/S0363-5023(03) 00148-5.

17. Latko WA, Armstrong TJ, Franzblau A, Ulin SS, Werner RA, Albers JW. Cross-sectional study of the relationship between repetitive work and the prevalence of upper limb musculoskeletal disorders. Am J Ind Med. 1999;36(2):248-59, https://doi.org/10.1002/(SICI)1097-0274 (199908)36:2\%3C248::AID-AJIM4\%3E3.3.CO;2-H.

18. Barnhart S, Demers PA, Miller M, Longstreth WT Jr., Rosenstock L. Carpal tunnel syndrome among ski manufacturing workers. Scand J Work Environ Health. 1991;17(1):46-52, https://doi.org/10.5271/sjweh.1735.

19. Resende LA, Alves RP, Castro HA, Kimaid PA, Fortinguerra CR, Schelp AO. Silent period in carpal tunnel syndrome. Electromyogr Clin Neurophysiol. 2000;40(1):31-6.

20. Girlanda P, Quartarone A, Sinicropi S, Pronesti C, Nicolosi C, Macaione V, et al. Electrophysiological studies in mild idiopathic carpal tunnel syndrome. Electroencephalogr Clin Neurophysiol. 1998;109(1):44-9, https://doi.org/10.1016/S09 24-980X(97)00076-3.

21. Koyuncuoglu HR, Kutluhan S, Yesildag A, Oyar O, Guler K, Ozden A. The value of ultrasonographic measurement in carpal tunnel syndrome in patients with negative electrodiagnostic tests. Eur J Radiol. 2005;56(3):365-9, https://doi. org/10.1016/j.ejrad.2005.05.013.

22. Jesensek Papez B, Palfy M, Mertik M, Turk Z. Infrared thermography based on artificial intelligence as a screening method for carpal tunnel syndrome diagnosis. J Int 
Med Res. 2009;37(3):779-90, https://doi.org/10.1177/1473 23000903700321.

23. Deniz FE, Oksüz E, Sarikaya B, Kurt S, Erkorkmaz U, Ulusoy $\mathrm{H}$, et al. Comparison of the diagnostic utility of electro- myography, ultrasonography, computed tomography, and magnetic resonance imaging in idiopathic carpal tunnel syndrome determined by clinical findings. Neurosurgery. 2012;70(3): 610-6, https://doi.org/10.1227/NEU.0b013e318233868f.

This work is available in Open Access model and licensed under a Creative Commons Attribution-NonCommercial 3.0 Poland License - http://creativecommons.org/ licenses/by-nc/3.0/pl/deed.en. 